\title{
Determination of cytokines in synovial fluids: correlation with diagnosis and histomorphological characteristics of synovial tissue
}

\author{
P Kahle, J G Saal, K Schaudt, J Zacher, P Fritz, G Pawelec
}

\begin{abstract}
In a study aimed at correlating cytokine levels in synovial fluid with the pathology of rheumatoid arthritis (RA), tumour necrosis factor $\alpha$, interleukin $1 \beta$ and interferon $\gamma$ were immunoassayed in 27 patients with RA, 16 patients with other arthritides, 23 with osteoarthritis, 13 patients with trauma, and 18 patients at necropsy without inflammatory disease and not known to have had joint disease (median 27 hours after death). The results for interleukin $1 \beta$ clearly show higher cytokine levels in patients with RA and other arthritides than in patients with osteoarthritis, trauma, or the patients at necropsy. Interferon $\gamma$ levels in patients with osteoarthritis and the patients at necropsy, however, were significantly greater than in patients with RA, and tumour necrosis factor $\alpha$ levels were also greater in the patients at necropsy compared with patients with RA. This study also correlated histomorphological patterns of synovitis and indicators of local inflammatory activity with synovial fluid cytokine levels, showing, for example, a positive association of interleukin $1 \beta$ titre and a negative association of interferon $\gamma$ titre with ulcerogranulomatous synovitis (itself associated with RA). Taken together, these results extend and strengthen data suggesting a possible part played by increased synovial fluid levels of interleukin $1 \beta$ in joint destruction in RA, but provide no evidence for increases in levels of tumour necrosis factor $\alpha$ or interferon $\gamma$ affecting the disease pathology.
\end{abstract}

Several cytokines which function as immunological mediators of inflammation may also cause joint destruction in rheumatoid arthritis (RA). ${ }^{12}$ Interleukin 1 stimulates the secretion of prostaglandin $E_{2}$, platelet derived growth factor, and collagenase by fibroblasts and chondrocytes, and the proliferation of fibroblasts and their production of fibronectin, type I collagen, and proteoglycans. Tumour necrosis factor $\alpha$ also stimulates fibroblast and chondrocyte production of prostaglandin $E_{2}$ and collagenase, bone resorption, and fibroblast proliferation. Various other factors have also been implicated, such as interleukin 6 , which stimulates the acute phase production of proteins such as $\mathrm{C}$ reactive protein, and enhances antibody production including rheumatoid factors, ${ }^{2}$ and interferon $\gamma$ which stimulates the expression of major histocompatibility complex class II molecules on synovial cells, implicated in triggering autoimmune $T$ cells.

According to several papers, these cytokines are found in the synovial fluid of patients with
RA, which supports their part in the immunopathology of RA. Several other cytokines, including the major $\mathrm{T}$ cell growth factor interleukin $2,{ }^{3}$ are, however, not found in synovial fluid either by bioassay, immunoassay, or as mRNA. Moreover, whereas there seems to be a consensus on interleukin 1 and interleukin 6 , several workers have reported low levels or the absence of interferon $\gamma^{+6}$ and tumour necrosis factor $\alpha^{5}$ in synovial fluid from patients with RA, and deficient secretion of interferon $\gamma$ and tumour necrosis factor $\gamma$ by stimulated peripheral blood mononuclear cells. ${ }^{78}$ One problem in interpreting the previous studies on the cytokine content in synovial fluid is the absence of normal control subjects which leaves open the possibility that findings in patients with RA may not necessarily be abnormal. Most studies have compared cytokine levels in patients with RA with those in patients with osteoarthritis or trauma, and conclusions on increased cytokine levels therefore are not necessarily relevant to normal joints. Where synovial fluid from non-arthritic subjects has been examined, levels of tumour necrosis factor $\alpha$ and interferon $\gamma$ higher than in patients with RA have sometimes been reported. ${ }^{5}$

As it is almost impossible to obtain synovial fluid from the joints of normal volunteers, this study determined interleukin $1 \beta$, tumour necrosis factor $\alpha$, and interferon $\gamma$ in synovial fluid from 14-18 patients at necropsy not known to have had rheumatoid arthritis less than 48 hours after death. These results were then compared with groups of patients with RA, other arthritides, osteoarthritis, and trauma.

\section{Patients and methods} SUBJECTS

Twenty seven patients with RA diagnosed according to the 1987 American Rheumatism Association criteria and attending the RobertBosch Hospital, Stuttgart or the University Hospitals, Tübingen were studied. The median age was 59 years (range $35-79$ ), 60\% were women, and $75 \%$ were positive for rheumatoid factor. Sixteen patients with other arthritides (two with gout, three with calcium pyrophosphate deposition disease, one with salmonella reactive arthritis, one with campylobacter reactive arthritis, one with Lyme disease, one with psoriatic arthritis, and seven unclassified arthritides (median age 41 years, range $20-76,31 \%$ women)) were also studied. Another 23 patients with osteoarthritis (median age 58 years, range $17-79,48 \%$ women), were included. Thirteen had acute traumatic knee injuries (median age 29 years, 
range $18-61,15 \%$ women). Synovial fluid was obtained by standard procedures for diagnostic and research purposes after informed consent. Synovial fluid was also drawn from knee joints of 18 patients at necropsy without joint effusions and not known to have had rheumatic disease (median age 60 years, range 46-84, 39\% women). The necropsy patients had been kept at $4^{\circ} \mathrm{C}$ with a median time after death of 27 hours (range 10-34 hours) and there was no obvious correlation between synovial cytokine concentration and the time elapsed between death and joint puncture.

\section{HISTOLOGY}

Joint capsules were obtained during synovectomy or arthroplasty of knee joints. Histological analysis of haematoxylin-eosin stained sections of synovial tissue was carried out according to standard procedures following Athanasou et al ${ }^{9}$ without knowledge of clinical data. Crystals were identified with a polarising microscope.

The following histological parameters were graded from 1 (absent) to 4 (obvious): formation of villi; hypertrophy and hyperplasia of lining cells; presence of 'transformed appearing cells'10; presence of lining cell ulceration; deposits of fresh and old fibrin; inflammatory reactions of diffuse, follicular, nodular, or perivascular types; amount of lymphocytes, plasma cells, histiocytes and granulocytes; amount of Russell's bodies; fibrosis of the joint capsule; oedema; proliferation of blood vessels; haemorrhage; haemosiderin deposits; giant cells; granuloma formation; and presence of crystals.

From these data, irrespective of the clinical diagnosis, seven histomorphological patterns of synovitis were defined: ${ }^{10}(a)$ granulomatous synovitis; $(b)$ crystal induced synovitis; (c) villonodular synovitis; $(d)$ synovitis characterised by the presence of transformed appearing cells with elongated nuclei and sparse chromatin without distinct cell membranes (designated 'fit synovitis'); (e) synovitis characterised by the presence of ulcerations of the synovial lining cells showing granulation tissue in more than one high power magnification field (designated ulcerous synovitis); $(f)$ synovitis with focal or diffuse lymphoplasmacellular inflammatory reaction in the absence of features of fit or ulcerous synovitis (designated lymphoplasmacellular synovitis); and $(g)$ synovitis where $(d)$ and $(f)$ were absent (designated serofibrous synovitis).

Acute or chronic inflammatory activity was defined by grading the amount of granulocytes or fibrin, or both, or the number of lymphoplasmacellular elements respectively.

Of these parameters, in this study population, there was a significant $(p<0.05)$ association between RA and acute but not chronic inflammatory activity, between RA and ulcerous synovitis, between osteoarthritis and serofibrous synovitis, and between RA and fibrotic changes (Kahle P, unpublished data).

\section{IMMUNOASSAYS}

Tumour necrosis factor $\alpha$ and interferon $\gamma$ were determined by radioimmunoassay kits purchased from Medgenix (Düsseldorf, Germany). Interleukin $1 \beta$ was measured in an enzyme linked immunoassay (ELISA) using kits from Cistron Biotechnology (Pine Brook, NJ, USA). The tumour necrosis factor $\alpha$, interferon $\gamma$, and interleukin $1 \beta$ assays had sensitivities of 10 $\mathrm{pg} / \mathrm{ml}, 1 \mathrm{U} / \mathrm{ml}$, and $20 \mathrm{pg} / \mathrm{ml}$ respectively. The tumour necrosis factor $\alpha$ assay showed no cross reactivity with tumour necrosis factor $\beta$, interleukin 1 , interleukin 2 nor interferons; the interferon $\gamma$ assay did not react with up to $10^{3}$ $\mathrm{U} / \mathrm{ml}$ interferon $\beta$, and the interleukin $1 \beta$ assay showed no cross-reactivity on interleukin $l \alpha$, interleukin 2, tumour necrosis factor $\alpha$, nor interferon $\gamma$ (manufacturers' data). Results obtained using these kits were transferred directly from the measuring device ( $\gamma$ counter or ELISA reader) to a $\mathrm{PC}$ for data analysis using in house computer programs (Schaudt et al, in preparation).

\section{STATISTICAL ANALYSIS}

Student's $t$ test was used for parametric analyses, whereas the Mann-Whitney U test was used for non-parametric analysis.

\section{Results}

Table 1 shows the results of measuring levels of interleukin $1 \beta$, tumour necrosis factor $\alpha$, and interferon $\gamma$ in the same samples of synovial fluid from donors with rheumatoid arthritis, other arthritides, osteoarthritis, trauma, or from patients at necropsy. There is a clear and significant increase of interleukin $1 \beta$ in patients with RA and other arthritides compared with the other three groups. Only small amounts of tumour necrosis factor $\alpha$ or interferon $\gamma$ were found in synovial fluid from patients with RA. The highest levels of tumour necrosis factor $\alpha$ and interferon $\gamma$ were found in synovial fluid in patients at necropsy, and these were significantly greater than in patients with RA. For tumour necrosis factor $\alpha$, only synovial fluid from patients at necropsy contained large amounts of this cytokine, whereas synovial fluid from patients at necropsy and patients with osteoarthritis contained large amounts of interferon $\gamma$. Synovial fluid from patients with trauma

Table 1 Cytokine levels in synovial fluid. Values are mean (SEM).

\begin{tabular}{|c|c|c|c|c|c|}
\hline \multirow[t]{2}{*}{ Cytokine } & \multicolumn{5}{|c|}{ Subject groups } \\
\hline & $\begin{array}{l}\text { Rheumatoid } \\
\text { arthritis }\end{array}$ & Other arthritides & Osteoarthritis & Trauma & $\begin{array}{l}\text { Patients at } \\
\text { necropsy }\end{array}$ \\
\hline $\begin{array}{l}\text { Interleukin } 1 /(\mathrm{pg} / \mathrm{ml}) \\
\text { Interferon } \gamma(\mathrm{U} / \mathrm{ml}) \\
\text { Tumour necrosis factor } \alpha(\mathrm{ng} / \mathrm{ml})\end{array}$ & $\begin{array}{l}193(57) \\
0 \cdot 6(0 \cdot 2) \\
0 \cdot 17(0 \cdot 04)\end{array}$ & $\begin{array}{l}211(125) \\
2 \cdot 4(1 \cdot 0) \\
0.97(0.60)\end{array}$ & $\begin{array}{l}21(13)^{*} \\
23 \cdot 8(14 \cdot 0)^{*} \\
0.08(0.03)\end{array}$ & $\begin{array}{l}<20 \\
4 \cdot 7(2 \cdot 1) \\
0.62(0.55)\end{array}$ & $\begin{array}{l}<20 \\
38 \cdot 8(13)^{*} \\
2 \cdot 89(0 \cdot 89)^{*}\end{array}$ \\
\hline
\end{tabular}

${ }^{*}$ Significantly $(p<0.05)$ different from the RA value. 
Table 2 Correlation between mean synovial fluid cytokine levels and the histomorphological pattern of synovitis.

\begin{tabular}{|c|c|c|c|c|}
\hline \multirow[t]{2}{*}{ Cytokine } & \multicolumn{4}{|c|}{ Histomorphological subtvpe of svnovitis } \\
\hline & $\begin{array}{l}s f \\
(n=18)\end{array}$ & $\begin{array}{l}\operatorname{lvp} \\
(n=10)\end{array}$ & $\begin{array}{l}u g \\
(n=13)\end{array}$ & $\begin{array}{l}f i t \\
(n=5)\end{array}$ \\
\hline $\begin{array}{l}\text { Interleukin } 1 /(\mathrm{pg} / \mathrm{ml}) \\
\text { Interferon } \gamma(\mathrm{U} / \mathrm{ml}) \\
\text { Tumour necrosis factor } \alpha(\mathrm{ng} / \mathrm{ml})\end{array}$ & $\begin{array}{l}31 \\
9 \cdot 3 \\
0 \cdot 09\end{array}$ & $\begin{array}{l}191 \\
0 \cdot 0 \\
0 \cdot 32\end{array}$ & $\begin{array}{l}144 t \\
0.5 t \\
0.15 \dagger\end{array}$ & $\begin{array}{l}412 \\
0 \cdot 0 \\
0 \cdot 16\end{array}$ \\
\hline
\end{tabular}

*(sf) serofibrous; (lyp) lymphoplasmacellular; (ug) ulcerogranulomatous; (fit) 'transformed appearing cell' synovitis.

†Significantly increased or decreased $(p<0.05)$ compared to the sf group.

Table 3 Correlation between synovial fluid cytokine levels and parameters of local inflammation.

\begin{tabular}{|c|c|c|c|c|}
\hline \multirow[t]{2}{*}{ Parameter } & \multicolumn{4}{|c|}{ Histological grade } \\
\hline & $l$ & 2 & 3 & 4 \\
\hline $\begin{array}{l}\text { Acute inflammation } \\
\text { No of patients } \\
\text { Mean interleukin } 1 \mathrm{f}(\mathrm{pg} / \mathrm{ml}) \\
\text { Mean interferon } \gamma(\mathrm{U} / \mathrm{ml}) \\
\text { Mean tumour necrosis factor } \alpha(\mathrm{ng} / \mathrm{ml})\end{array}$ & $\begin{array}{l}15 \\
23 \\
8 \cdot 9 \\
0 \cdot 23\end{array}$ & $\begin{array}{l}7 \\
46 \\
5 \cdot 4 \\
0 \cdot 16\end{array}$ & $\begin{array}{l}16 \\
266 \dagger \\
0 \cdot 3 \dagger \\
0 \cdot 14\end{array}$ & $\begin{array}{l}9 \\
154 t \\
0 \cdot 5 t \\
0 \cdot 14\end{array}$ \\
\hline $\begin{array}{l}\text { Chronic inflammation } \\
\text { No of patients } \\
\text { Mean interleukin } 1 \beta(\mathrm{pg} / \mathrm{ml}) \\
\text { Mean interferon } \gamma(\mathrm{U} / \mathrm{ml}) \\
\text { Mean tumour necrosis factor } \alpha(\mathrm{ng} / \mathrm{ml})\end{array}$ & $\begin{array}{l}0 \\
- \\
-\end{array}$ & $\begin{array}{l}10 \\
25 \\
3 \cdot 8 \\
0 \cdot 07\end{array}$ & $\begin{array}{l}27 \\
66+ \\
5 \cdot 7 \\
0 \cdot 23\end{array}$ & $\begin{array}{l}13 \\
360 \dagger \\
0 \cdot 2 \dagger \\
0 \cdot 12\end{array}$ \\
\hline $\begin{array}{l}\text { Fibrotic inflammation } \\
\text { No of patients } \\
\text { Mean interleukin } 1(;(\mathrm{pg} / \mathrm{ml}) \\
\text { Mean interferon } \gamma(\mathrm{U} / \mathrm{ml}) \\
\text { Mean tumour necrosis factor } \alpha(\mathrm{ng} / \mathrm{ml})\end{array}$ & $\begin{array}{l}9 \\
28 \\
5 \cdot 0 \\
0 \cdot 40\end{array}$ & $\begin{array}{l}15 \\
95 \\
3 \cdot 5 \\
0 \cdot 08\end{array}$ & $\begin{array}{l}19 \\
229 \\
0 \cdot 6 \\
0 \cdot 12\end{array}$ & $\begin{array}{l}6 \\
296 \\
2 \cdot 8 \\
1 \cdot 79\end{array}$ \\
\hline
\end{tabular}

:(Grade 1), none detected; (grade 2) just detectable; (grade 3) unequivocal; (grade 4) obvious.

† Significantly $(\mathbf{p}<\mathbf{0 . 0 5})$ different from grade 1 (or grade 2 for chronic inflammation).

contained more interferon $\gamma$ and tumour necrosis factor $\alpha$ than synovial fluid from patients with RA, but this did not reach significance.

Table 2 shows that the interleukin $1 \beta$ titre was significantly positively associated with the ulcerogranulomatous pattern of synovitis (ulcerous synovitis) compared with the serofibrous synovitis pattern (not associated with RA). Furthermore, there is also an association between the presence of transformed appearing cells in the synovial membrane and the interleukin $1 \beta$ titre. In contrast, interferon $\gamma$ showed a negative association with ulcerous synovitis and a significant positive association with low activity serofibrous synovitis. Although the tumour necrosis factor $\alpha$ titre was low, it was also significantly increased in ulcerous compared with serofibrous synovitis.

Of further interest were the significant positive associations between histologically defined grades of acute and chronic inflammatory activity in synovial tissue biopsy samples and the amount of synovial fluid interleukin $1 \beta$ (table 3). There was also a (non-significant) trend towards the same association between synovial fluid interleukin $1 \beta$ content and grade of histological fibrosis assigned to the tissue (table 3). In contrast to interleukin $1 \beta$, interferon $\gamma$ correlated negatively with acute and chronic inflammation. Only the former correlationreached statistical significance, however. Tumour necrosis factor $\alpha$ did not show any significant associations with acute, chronic nor fibrotic inflammation.

\section{Discussion}

The data presented here are consistent with the consensus that levels of interleukin $1 \beta$ are increased in the synovial fluid of patients with
$\mathrm{RA}^{\mathrm{l}}$ as well as in their serum. ${ }^{11}$ It is further implied that interleukin $1 \beta$ titres are associated with joint pathology by the novel finding of a significant quantitative correlation between levels of interleukin $1 \beta$ in synovial fluid and certain histomorphological patterns of synovitis (table 2). Thus, for example, in independent analyses, ulcerogranulomatous synovitis was found to be significantly positively associated with $\mathrm{RA},{ }^{10}$ and is here shown to be positively associated with the interleukin $1 \beta$ titre. Grades of acute or chronic inflammation, as well as fibrotic status in synovial biopsy samples, have also been correlated with cytokine titres (table 3 ). These data are consistent with a report that the level of interleukin $1 \beta$ in serum samples correlates with clinical disease activity, ${ }^{11}$ but this had not previously been shown directly in the joint. In agreement with the supposition that synovial fluid from normal joints contains less or no interleukin $1 \beta$, data presented here show that not only do synovial fluid samples from patients with trauma and osteoarthritis contain little interleukin $1 \beta$, but that synovial fluid from patients at necropsy has none. So far, there has been little possibility of measuring cytokine levels in normal joints, and our results with patients at necropsy reflect an attempt to find a group of control subjects without rheumatic disease. Where 'normal' joints have been examined previously, little interleukin $1 \beta$ has been found.

In contrast to results for interleukin $1 \beta$, reports on the presence of interferon $\gamma$ and tumour necrosis factor $\alpha$ in synovial fluid from patients with rheumatoid arthritis have been contradictory. This may in part be due to the different immunoassays or even bioassays used to determine the cytokines. Several workers found little or no tumour necrosis factor $\alpha$ and interferon $\gamma$ in synovial fluid from patients with rheumatoid arthritis; ${ }^{4-6} 12$ others did succeed in showing their presence, albeit sometimes only in a fraction of patients with RA. ${ }^{13}$ For example, in one study of 59 patients with $R A$, very high levels of tumour necrosis factor $\alpha$ were found in only one synovial fluid sample, high levels in two, detectable levels in a further 16, and none in the remaining 40 either by bioassay or immunoassay. ${ }^{14}$ In the studies where these two cytokines were found, it was difficult to judge whether their presence was pathological because normal controls were not included. Some workers have found large amounts of these cytokines in 'normal' control subjects and low levels or none in patients with $R A,{ }^{5}$ a result in agreement with the present data on synovial fluid from patients at necropsy and patients with RA. Other workers have found tumour necrosis factor $\alpha$ in synovial fluid from patrients with RA but only low levels in 'normal' synovial fluid (actually from patients with trauma). ${ }^{15}$ Compared with the results on synovial fluid from patients at necropsy we also found low levels of tumour necrosis factor $\alpha$ in synovial fluid from patients with trauma, so these results may not be discrepant as seems at first sight.

The presence of relatively low levels of tumour necrosis factor $\alpha$ and interferon $\gamma$ in most synovial fluid samples from patients with 
RA may also be consistent with several reports of defects in the ability of RA lymphocytes to secrete these cytokines after stimulation in vitro, ${ }^{7816}$ though even this is not always observed. ${ }^{17}$ Tumour necrosis factor $\alpha$ is not generally present in serum samples from normal donors, but tumour necrosis factor was shown in serum samples from patients with RA. ${ }^{18}$ Tetta $e t$ al used a variant bioassay for tumour necrosis factor which did not distinguish between tumour necrosis factor $\alpha$ and tumour necrosis factor $\beta$, and may also have been affected by other factors. ${ }^{18}$ Unlike interferon $\gamma$, however, tumour necrosis factor $\alpha$ is secreted by synovial tissue itself, ${ }^{15}$ so secretion by peripheral blood mononuclear cells may not reflect synovial fluid levels.

Thus, taken together with the present results, a consensus from published work allows the conclusion that in synovial fluid from patients with RA, interleukin $1 \beta$ is generally increased, interferon $\gamma$ is generally decreased, and tumour necrosis factor $\alpha$ is equivocal, with a few patients having increased tumour necrosis factor $\alpha$ but most decreased tumour necrosis factor $\alpha$. This may reflect heterogeneity in the RA processes or disease stage, as well as different techniques for the measurement of tumour necrosis factor $\alpha$. In the synovial fluid of 27 patients with rheumatoid arthritis with a mean of $0.17 \mathrm{ng} / \mathrm{ml}$ tumour necrosis factor $\alpha$ (table 1), only one patient clearly had an increased level $(0.98 \mathrm{ng} / \mathrm{ml}$, data not shown), similar to the results of Duff $e t a l$, where at most only three of 59 patients had high levels of tumour necrosis factor $\alpha$ in their synovial fluid, ${ }^{14}$ and of Westacott et al, where only two of 54 patients with RA had synovial fluid with $>1 \mathrm{ng} / \mathrm{ml}$ of tumour necrosis factor $\alpha$. In the light of these results, it could even be questioned whether RA could be viewed as associated with a deficiency in the production of the inflammatory cytokines tumour necrosis factor $\alpha$ and interferon $\gamma$, rather than a dysregulated pathological increase. This would be consistent with the fact that several drugs used to treat RA are known to potentiate aspects of immune responsiveness by blocking prostaglandin $\mathrm{E}_{2}$ production or by enhancing cytokine secretion. ${ }^{20}$ Tumour necrosis factor $\alpha$ and interferon $\gamma$ are generally thought of as substances involved in the upregulation of the immune response, but they may also participate in negative regulatory control, by direct growth inhibitory effects, or by immunoregulation. Thus, for example, tumour necrosis factor $\alpha$ (but not interferon $\gamma$ ) has been shown to inhibit selectively clonal expansion of a subset of helper $T$ cells. ${ }^{21}$ Cytokine networks within the rheumatoid joint are, however, clearly more complex than understood at present and other identified factors such as interleukin $8^{22}$ are likely to play a part in the pathological process. Therefore, much more needs to be established before substitution treatments designed to correct cytokine defects acquire a convincing rationale. Nonetheless, a preliminary report on the treatment of RA with interferon $\gamma$ has illustrated the potential value of this approach. ${ }^{23}$

This work was supported in part by the Deutsche Forschungsgemeinschaft (SFB 120) and by the Robert Bosch Foundation. The assistance of Ms A Rehbein and Ms S Koch is gratefully acknowledged. This work forms part of the MD thesis of $P$ Kahle.

1 Lipsky P E, Davis L S, Cush J J, Oppenheimer-Marks N The role of cytokines in the pathogenesis of rheumatoid arthritis. Springer Semin Immunopathol 1989; 11: 123-62.

2 Arend W P, Dayer J-M. Cytokines and cytokine inhibitors or antagonists in rheumatoid arthritis. Arthritis Rheum 1990; 33: 305-15.

3 Firestein G S, Xu W-D, Townsend $\mathrm{K}$, et al. Cytokines in chronic inflammatory arthritis. I. Failure to detect $T$ cell lymphokines (interleukin 2 and interleukin 3 ) and presence of macrophage colony-stimulating factor (CSF-1) and a of macrophage colony-stimulating factor (CSF-1) and a novel mast cell growth factor
f Exp Med 1988; 168: 1573-86.

4 Yamagata N, Kobayashi K, Kasama T, et al. Multiple cytokine activities and loss of interleukin 2 inhibitor in synovial fluids of patients with rheumatoid arthritis. f Rheumatol 1988; 15: 1623-7.

5 Westacott C I, Whicher J T, Barnes I C, Thompson D, Swan A J, Dieppe P A. Synovial fluid concentration of five different cytokines in rheumatic diseases. Ann Rheum Dis 1990; 49: 676-81

6 Firestein G S, Zvaifler N J. Peripheral blood and synovial fluid monocyte activation in inflammatory arthritis. II. Low levels of synovial fluid and synovial tissue interferon suggest that $\gamma$-interferon is not the primary macrophage suggest that $\gamma$-interferon is not the primary macr
activating factor. Arthritis Rheum 1987; 30: 864-71.

7 Malaise M G, Franchimont P. Defective in vitro $\gamma$ interferon palaise M G, Franchimont $P$. Defective in vitro $\gamma$ interferon
production in rheumatoid arthritis. Arthritis Rheum 1987; production

8 Stolzenburg T, Binz H, Fontana A, Felder M, Wagenhaeuser F-J. Impaired mitogen-induced interferon- $\gamma$ production in rheumatoid arthritis and related diseases. Scand $\mathcal{F}$ Immunol 1988; 27: 73-81.

9 Athanasou N A, Quinn J, Heryet A, Puddle B, Woods C G, McGee J O D. The immunohistology of synovial lining cells in normal and inflamed synovium. $\mathcal{F}$ Pathol $1988 ; 155$ 133-42.

10 Fritz P, Laschner W, Saal J G, Deichsel G, Tuczek H V, Wegner G. Histological classification of synovitis. Zentralbl Allg Pathol 1990; 135: 729-41.

11 Eastgate J A, Wood N C, Di Giovine F S, Symons J A, Grinlinton F M, Duff G W. Correlation of plasma Grinlinton F M, Duff $\mathrm{G}$ W. Correlation of plasma
interleukin I levels with disease activity in rheumatoid arthritis. Lancet 1988; ii: 706-9.

12 Hopkins S J, Meager A, Cytokines in synovial fluid: II. The presence of tumour necrosis factor and interferon. Clin Exp Immunol 1988; 73: 88-92.

13 Saxne T, Palladino $M A, J r$, Heinegărd $D$, Talal $N$, Wollheim F A. Detection of tumour necrosis factor $\alpha$ but not tumor necrosis factor $\beta$ in rheumatoid arthritis synovial fluid and serum. Arthritis Rheum 1988; 31: 1041-5.

14 Duff G W, Dickens E, Wood N, Manson J, Symons J, Poole $S$, di Giovine $F$. Immunoassay, bioassay and in situ hybridisation of monokines in human arthritis. In: Progress hybridisation of monokines in human arthritis. In: Progress in leukocyte biology 8. Monokines and other
cytokines. New York: Liss, 1988: 387-92.

15 Yocum D E, Esparza L, Dubry S, Benjamin J B, Volz R, Scuderi P. Characteristics of tumor necrosis factor proScuderi $P$. Characteristics of tumor necrosis factor pro-
duction in rheumatoid arthritis. Cell Immunol 1989; 122: duction

16 Franchimont $P$, Reuter A, Vrindts-Gevaert Y, et al. Production of tumour necrosis factor $\alpha$, interferon-gamma and interleukin- 2 by peripheral blood mononuclear cells of subjects suffering from rheumatoid arthritis. Scand $\mathcal{f}$ Rheumatol 1988; 17: 203-12.

17 McKenna R M, Wilkins J A, Warrington R J. Lymphokine production in rheumatoid arthritis and systemic lupus erythematosus. $\mathcal{7}$ Rheumatol $1988 ; 15$ : 1639-42.

18 Tetta C, Camussi G, Modena V, Di Vittorio C, Baglioni C. Tumour necrosis factor in serum and synovial fluid of patients with active and severe rheumatoid arthritis. Ann Rheum Dis 1990; 49: 665-7.

19 Firestein G S, Alvaro-Garcia J M, Maki R. Quantitative analysis of cytokine gene expression in rheumatoid analysis of cytokine gene expression

20 Oben J A, Wallace G R, Chain B M, Foreman J C. The stimulation of IL-2 production by anti-rheumatic drugs. stimulation of IL-2 production

21 Pawelec G P, Rehbein A, Schaudt K, Busch F W. IL-4 responsive human helper $T$ cell clones are resistant to growth inhibition by tumour necrosis factor- $(t . \mathcal{F}$ Immunol 1989; 143: 902-6.

22 Brennan F M, Zachariae C O C, Chantry D, et al. Detection of interleukin 8 biological activity in synovial fluids from patients with rheumatoid arthritis and production of interleukin 8 mRNA by isolated synovial cells. Eur $\mathcal{f}$ Immunol 1990; 20: 2141-4.

23 Cannon G W, Pincus S H, Emkey R D, et al. Double-blind trial of recombinant $\gamma$-interferon versus placebo in the treatment of rheumatoid arthritis. Arthritis Rheum 1989; 32: 964-73. 